\title{
Prevalence of diagnosed type 1 and type 2 diabetes among US adults in 2016 and 2017: population based study
}

\author{
Guifeng Xu, ${ }^{1}$ Buyun Liu, ${ }^{1}$ Yangbo Sun, ${ }^{1}$ Yang Du, ${ }^{1}$ Linda G Snetselaar, ${ }^{1}$ Frank B Hu, ${ }^{2,3,4}$ \\ Wei Bao ${ }^{1,5,6}$
}

${ }^{1}$ Department of Epidemiology,

College of Public Health,

University of lowa, lowa City, IA

52242, USA

${ }^{2}$ Department of Nutrition, Harvard TH Chan School of

Public Health, Boston, MA, USA

${ }^{3}$ Department of Epidemiology,

Harvard TH Chan School of

Public Health, Boston, MA, USA

${ }^{4}$ Channing Division of Network

Medicine, Department of

Medicine, Brigham and

Women's Hospital and Harvard

Medical School, Boston, MA,

USA

${ }^{5}$ Obesity Research and

Education Initiative, University

of lowa, lowa City, IA, USA

${ }^{6}$ Fraternal Order of Eagles

Diabetes Research Center,

University of lowa, lowa City,

IA, USA

Correspondence to: W Bao

wei-bao@uiowa.edu

Additional material is published online only. To view please visit the journal online.

Cite this as: BMJ 2018;361:k1497 http://dx.doi.org/10.1136/bmi.k1497

Accepted: 27 August 2018

\section{ABSTRACT}

OBJECTIVE

To estimate the prevalence of diagnosed total diabetes, type 1 diabetes, and type 2 diabetes in the US general population and the proportions of each among US adults with a diagnosis of diabetes.

DESIGN

Nationwide, population based, cross sectional survey.

SETTING

National Health Interview Survey, 2016 and 2017.

\section{PARTICIPANTS}

Adults aged 20 years or older $(n=58186)$, as a nationally representative sample of the civilian, non-institutionalized US population.

\section{MAIN OUTCOME MEASURES}

Prevalence of diagnosed diabetes, type 1 diabetes, and type 2 diabetes in the US general population, and the proportions of each subtype in participants with a diagnosis of diabetes.

RESULTS

Among the 58186 included adults, 6317 had received a diagnosis of diabetes. The weighted prevalence of diagnosed diabetes, type 1 diabetes, and type 2 diabetes among US adults was 9.7\% (95\% confidence interval $9.4 \%$ to $10.0 \%), 0.5 \%(0.5 \%$ to $0.6 \%$ ), and $8.5 \%$ (8.2\% to $8.8 \%$ ), respectively. Type 1 diabetes was more prevalent among adults with lower education level, and type 2 diabetes was more prevalent among older adults, men, and those with lower educational level, lower family income level, and higher body mass index (BMI). Among adults with a diagnosis of diabetes, the weighted percentage of type 1 and type 2 diabetes was 5.6\% (4.9\% to $6.4 \%$ ) and $91.2 \%$ (90.4\% to $92.1 \%$ ), respectively. The percentage of type 1 diabetes was higher among younger adults (age 20-44 years), non-Hispanic white people, those with higher education level, and those with lower BMI, whereas the percentage of

\section{WHAT IS ALREADY KNOWN ON THIS TOPIC}

Although studies have reported the prevalence of diabetes among adults in the United States and worldwide, data on prevalence of diabetes by subtypes are scarce

Type 2 diabetes, the predominant form of diabetes, is assumed to account for $90 \%$ or more of all diabetes cases in adults

\section{WHAT THIS STUDY ADDS}

The prevalence of diagnosed type 1 and type 2 diabetes in 2016 and 2017 among US adults was $0.5 \%$ and $8.5 \%$, respectively

Among adults with diabetes, the weighted percentage of type 1 and type 2 diabetes was $5.6 \%$ and $91.2 \%$, respectively

type 2 diabetes was higher among older adults (age $\geq 65$ years), non-Hispanic Asians, those with lower education level, and those with higher BMI.

\section{CONCLUSION}

This study provided benchmark estimates on the national prevalence of diagnosed type 1 diabetes (0.5\%) and type 2 diabetes (8.5\%) among US adults. Among US adults with diagnosed diabetes, type 1 and type 2 diabetes accounted for $5.6 \%$ and $91.2 \%$, respectively.

\section{Introduction}

Diabetes, encompassing type 1 and type 2 diabetes and other subtypes, is a major public health concern in the United States and elsewhere. ${ }^{12}$ In 2015, 9.4\% of the US population ( 30.3 million people) was estimated to have diabetes. ${ }^{3}$ In the same year, the global number of adults with diabetes was estimated at 415 million, with a projected increase to 642 million by $2040 .^{2}$ Diabetes not only results in specific complications ${ }^{4}$ but also increases the risk of cardiovascular disease, ${ }^{5}$ cancer, ${ }^{6}$ and all cause mortality. ${ }^{7} 8$ The economic burden of diabetes in adults is substantial-roughly \$245bn (£174bn; €199bn) in the United States in $2012^{9}$ and $\$ 1.31$ tn worldwide in $2015 .^{10}$

The causes of type 1 and type 2 diabetes differ, as do the clinical manifestations and treatments. ${ }^{11}$ Type 2 diabetes-the predominant subtype of diabetes-mostly develops in adulthood. ${ }^{11}{ }^{12}$ In contrast, type 1 diabetes usually develops in childhood and is considered rare among adults. ${ }^{111314}$ Although previous studies in the United States ${ }^{15-17}$ and elsewhere ${ }^{18}$ have reported the prevalence of diabetes among adults on the basis of national health surveys, ${ }^{15-17}$ little is known about the prevalence by diabetes subtypes (eg, type 1 and type 2 diabetes) in adulthood.

Because type 2 diabetes predominates among adults, ${ }^{111214}$ previous reported prevalence and trends in diabetes ${ }^{15-17}$ were likely representative of this subtype. With the continuing improvement in treatment of type 1 diabetes, ${ }^{1113}$ more children with this form of diabetes are expected to survive to adulthood.

Using data from the National Health Interview Survey (NHIS), one of the leading health surveys in the United States, we estimated the prevalence of diagnosed type 1 and type 2 diabetes in 2016 and 2017 and the proportions of these subtypes among US adults with a diagnosis of diabetes.

\section{Methods}

\section{Study population}

The NHIS is a continuous, nationwide cross sectional household interview survey conducted each year 
by the National Center for Health Statistics at the Centers for Disease Control and Prevention. The NHIS focuses on the civilian non-institutionalized population residing in the United States at the time of the interview. Exclusion criteria are those in long term care institutions and correctional facilities and US nationals living in foreign countries. Since its inception in 1957, the NHIS has become the principal source of information on the health status of the US population, ${ }^{19}$ and the data have been widely used in reports on diabetes prevalence and trends among US adults. $^{31520}$ The NHIS uses a multistage probability sampling, which enables nationally representative sampling. The multistage methods partition the target population into several nested levels of stratums and clusters. In 2016 and 2017, the NHIS surveyed a sample of 319 of 1700 geographically defined primary sampling units in each of the 50 states and in the District of Columbia. A primary sampling unit consists of a county, a small group of contiguous counties, or a metropolitan statistical area. The annual sample size for households is about 35000 containing about 87500 children and adults. A detailed description of the survey design, methods, and sample weights in the NHIS is published elsewhere. ${ }^{21}$ The NHIS was approved by the research ethics review board of the National Center for Health Statistics and US Office of Management and Budget. All respondents provided oral consent before participation.

\section{Data collection}

The NHIS collects data on a broad range of health topics through face-to-face household interviews. The total household response rate was $67.9 \%$ in 2016 and $66.5 \%$ in 2017 , and the conditional response rate for the adult sample was $80.9 \%$ in 2016 and $80.7 \%$ in 2017.

Respondents were asked whether they had ever been told by a health professional that they had diabetes or sugar diabetes. ${ }^{15}$ For women, this question specifically asked about diabetes other than during pregnancy. Approximately $99.9 \%$ of the adult participants in both NHIS 2016 and NHIS 2017 responded to this question.

Since 2016, the NHIS asked participants who had ever received a diagnosis of diabetes to report the subtypes (ie, type 1 or type 2, other types, or unknown). Among those with an ever diagnosis of diabetes, 96\% reported the subtype and only $4 \%$ reported unknown subtypes $(n=253)$ or refused to report subtypes $(n=3)$. In addition, the participants were asked about age at diabetes diagnosis, use of drugs, use of insulin, and timing of the initiation of insulin. Respondents who self reported type 1 diabetes and current insulin use were classified as having type 1 diabetes. Respondents who self reported other diabetes types were classified as having other type diabetes. All the remaining people with diabetes, except those who reported unknown subtypes or refused to report subtypes, were classified as having type 2 diabetes.

A standardized questionnaire was used to collect information on age, sex, race/ethnicity, education, family income, body weight, and height. Age was grouped into three categories: 20-44 years (younger adults), 45-64 years (middle aged adults), and 65 years and older (older adults). The participants self reported their race and Hispanic origin in response to specific questions. In this analysis, we categorized race/ethnicity into Hispanic, non-Hispanic white, nonHispanic black, non-Hispanic Asian, and other. The family income to poverty ratio is a measure of family income relative to poverty guidelines specific to the survey year. We classified family income levels into four categories: income poverty ratio <1.0, 1.0-1.9, 2.0-3.9, and $\geq 4.0$. Body mass index (BMI) was calculated as weight in kilograms divided by the square of height in meters.

\section{Statistical analysis}

In all analyses we used survey weights to account for unequal probabilities of selection, oversampling, and non-response in the survey. Therefore, all the reported estimates were representative of the civilian, noninstitutionalized US population.

Appendix figure 1 shows the flowchart of participant inclusion in the study. We estimated the weighted prevalence of diabetes and of type 1 and type 2 diabetes and the weighted percentages of type 1 and type 2 diabetes among those with an ever diagnosis of diabetes. Using the direct method, we age standardized stratified estimates by sex, race/ethnicity, family income, education, and BMI to allow comparisons independent of age. We age adjusted estimates to the 2010 US census population using standardizing proportions for the age groups 20-44 years, 45-64 years, and 65 years or older. The Rao-Scott $\chi^{2}$ test with an adjusted $F$ statistic was used to calculate the $P$ value for overall differences in prevalence or percentages across stratums. Logistic regression models were used to assess the associations of age, sex, race/ethnicity, family income, education, and BMI with prevalence of type 1 and type 2 diabetes.

All data analyses were conducted using survey procedures in SAS 9.4 (SAS Institute, Cary, NC). A two sided $\mathrm{P}$ value $<0.05$ was considered statistically significant.

\section{Patient involvement}

No patients were involved in setting the research question or the outcome measures, nor were they involved in developing plans for recruitment, design, or implementation of the study. No patients were asked to advise on interpretation or writing up of results. This study used deidentified information collected in a national health survey. There are no plans to disseminate the results of the research to study participants or the relevant patient community.

\section{Results}

Among the 58186 included adults aged 20 years or older, 6317 had received a diagnosis of diabetes. The weighted prevalence of diagnosed diabetes was 9.7\% (95\% confidence interval $9.4 \%$ to $10.0 \%$ ), which 
was comparable to that recorded for 2015 in the Centers for Disease Control and Prevention's latest National Diabetes Statistics Report. ${ }^{3}$ The prevalence of diagnosed diabetes differed statistically significantly by age, sex, race/ethnicity, education, family income, and BMI (table 1). The prevalence of diagnosed diabetes did not differ by survey year, with the weighted prevalence of $9.7 \%$ (9.3\% to $10.2 \%$ ) in 2016 and $9.7 \%$ (9.2\% to $10.1 \%$ ) in 2017.

The weighted prevalence of diagnosed type 1 diabetes, type 2 diabetes, and other subtypes was $0.5 \%(0.5 \%$ to $0.6 \%), 8.5 \%$ ( $8.2 \%$ to $8.8 \%$ ), and $0.3 \%$ $(0.2 \%$ to $0.3 \%)$, respectively. Type 1 diabetes was more prevalent among adults with lower education level, and type 2 diabetes was more prevalent among men and those with lower education level, lower family income level, and higher BMI (table 2). Among adults with a diagnosis of diabetes, the weighted percentage of type 1 and type 2 diabetes was 5.6\% (4.9\% to 6.4\%) and $91.2 \%$ (90.4\% to $92.1 \%$ ), respectively (table 2). The percentage of type 1 diabetes was higher among younger adults (age 20-44 years), non-Hispanic white people, those with higher education level, and those with lower BMI, whereas the percentage of type 2 diabetes was higher among older adults (age $\geq 65$ years), non-Hispanic Asians, those with lower education level, and those with higher BMI (table 2). In multivariable logistic regression models, we found that age, sex, race/ethnicity, education level, family income level, and BMI were statistically significant risk factors for diagnosed type 2 diabetes in adults, whereas sex, race/ethnicity, and family income level were statistically significantly associated with diagnosed type 1 diabetes (table 3).

\section{Discussion}

On the basis of information from a nationally representative survey in the United States in 2016 and 2017, we estimated that $0.5 \%$ of US adults had a diagnosis of type 1 diabetes and $8.5 \%$ had a diagnosis of type 2 diabetes. The prevalence of both subtypes varied statistically significantly by age, sex, race/ ethnicity, education, family income, and body mass index (BMI). Moreover, the patterns of these variables were distant between participants with diagnosed type 1 diabetes and those with diagnosed type 2 diabetes. Among US adults with a diagnosis of diabetes, type 1 diabetes accounted for $5.6 \%$ of cases and type 2 diabetes accounted for $91.2 \%$ of cases.

\section{Results in relation to other studies}

Previous national surveys among US adults have focused on the prevalence of diabetes regardless of the subtypes. ${ }^{15-17}$ Our estimates on prevalence of diabetes overall were comparable with those of previous studies. ${ }^{15-17}$ Little is known about the prevalence of type 1 and type 2 diabetes among US adults, and the paucity of such data not only applies to the US but to

\begin{tabular}{|c|c|c|c|c|}
\hline Characteristics & No of participants* & No with diabetes* & Prevalence, \% (95\% Cl)† & $P$ value \\
\hline Overall & 58186 & 6317 & 9.7 (9.4 to 10.0$)$ & \\
\hline Age adjusted & 58186 & 6317 & $9.3(9.0$ to 9.7$)$ & \\
\hline \multicolumn{5}{|l|}{ Age (years): } \\
\hline $20-44$ & 21794 & 632 & 2.9 (2.6 to 3.2$)$ & \multirow{3}{*}{0.001} \\
\hline $45-64$ & 20182 & 2512 & $12.4(11.7$ to 13.0$)$ & \\
\hline 65 & 16210 & 3173 & 19.8 (19.0 to 20.6) & \\
\hline \multicolumn{5}{|l|}{ Sex: } \\
\hline Men & 26313 & 3073 & $10.2(9.8$ to 10.6$)$ & \multirow{2}{*}{0.001} \\
\hline Women & 31873 & 3244 & $8.6(8.2$ to 9.0$)$ & \\
\hline \multicolumn{5}{|l|}{ Race/ethnicity: } \\
\hline Hispanic & 6651 & 778 & $13.4(12.2$ to 14.5$)$ & \multirow{5}{*}{0.001} \\
\hline Non-Hispanic white & 40779 & 4116 & $8.0(7.7$ to 8.4$)$ & \\
\hline Non-Hispanic black & 6214 & 945 & $13.1(12.1$ to 14.1$)$ & \\
\hline Non-Hispanic Asian & 2819 & 239 & $8.9(7.6$ to 10.2$)$ & \\
\hline Other & 1609 & 228 & 13.7 (11.2 to 16.2$)$ & \\
\hline \multicolumn{5}{|l|}{ Education level: } \\
\hline Below high school & 5461 & 1061 & $14.9(13.8$ to 16.1$)$ & \multirow{3}{*}{0.001} \\
\hline High school & 15307 & 1932 & $10.4(9.8$ to 11.0$)$ & \\
\hline Beyond high school & 37220 & 3296 & $7.9(7.6$ to 8.3$)$ & \\
\hline \multicolumn{5}{|c|}{ Family income level (IPR): } \\
\hline 1.0 & 6574 & 941 & $15.2(14.0$ to 16.3$)$ & \multirow{4}{*}{0.001} \\
\hline $1.0-1.9$ & 8729 & 1234 & 13.1 (12.2 to 14.1$)$ & \\
\hline $2.0-3.9$ & 14024 & 1478 & $9.4(8.8$ to 10.0$)$ & \\
\hline 4.0 & 19342 & 1566 & $7.1(6.6$ to 7.5$)$ & \\
\hline \multicolumn{5}{|l|}{$\mathrm{BMI}\left(\mathrm{kg} / \mathrm{m}^{2}\right):$} \\
\hline 25.0 & 19163 & 912 & $4.2(3.8$ to 4.5$)$ & \multirow[b]{4}{*}{ stratums } \\
\hline $25.0-29.9$ & 19627 & 1845 & $7.8(7.3$ to 8.2$)$ & \\
\hline 30.0 & 19396 & 3560 & 15.6 (15.0 to 16.2$)$ & \\
\hline \multicolumn{4}{|c|}{$\begin{array}{l}\text { BMI=body mass index; IPR=family income to poverty ratio. } \\
\text { *Unweighted number of participants and diabetes cases. } \\
\text { †All prevalence estimates were weighted. Overall and age group results were unadjusted, except when indicated otherwise. Results by other stratums } \\
\text { were age adjusted to } 2010 \text { US census population using age groups 20-44 years, } 45-64 \text { years, and } 65 \text { years or older. } \\
\text { †P value for overall differences across stratums. }\end{array}$} & \\
\hline
\end{tabular}




\begin{tabular}{|c|c|c|c|c|c|c|c|c|}
\hline \multirow[b]{2}{*}{ Characteristics } & \multicolumn{4}{|l|}{ Type 1 diabetes } & \multicolumn{4}{|l|}{ Type 2 diabetes } \\
\hline & Prevalence, \% (95\% Cl)† & P value $\ddagger$ & $\begin{array}{l}\% \text { of diagnosed total } \\
\text { diabetes }(95 \% \mathrm{Cl}) \dagger\end{array}$ & P valueł & Prevalence, \% $(95 \% \mathrm{Cl}) \dagger$ & Pvalue & $\begin{array}{l}\% \text { of diagnosed total } \\
\text { diabetes }(95 \% \mathrm{Cl}) \dagger\end{array}$ & P value \\
\hline Overall & $0.5(0.5$ to 0.6$)$ & & $5.6(4.9$ to 6.4$)$ & & $8.5(8.2$ to 8.8$)$ & & 91.2 (90.4 to 92.1$)$ & \\
\hline Age adjusted & $0.5(0.5$ to 0.6$)$ & & $9.9(8.1$ to 11.7$)$ & & $8.2(7.9$ to 8.5$)$ & & 85.0 (83.1 to 86.9$)$ & \\
\hline \multicolumn{9}{|l|}{ Age (years): } \\
\hline $20-44$ & $0.5(0.3$ to 0.6$)$ & \multirow{3}{*}{0.14} & 16.6 (12.8 to 20.4$)$ & \multirow{3}{*}{0.001} & 2.1 (1.8 to 2.3$)$ & \multirow{3}{*}{0.001} & 75.3 (71.1 to 79.4$)$ & \multirow{3}{*}{0.001} \\
\hline $45-64$ & $0.6(0.4$ to 0.7$)$ & & $4.6(3.6$ to 5.6$)$ & & 11.1 (10.5 to 11.7$)$ & & 92.4 (91.2 to 93.7$)$ & \\
\hline 65 & $0.6(0.5$ to 0.8$)$ & & $3.3(2.6$ to 4.1$)$ & & $18.2(17.4$ to 19.0$)$ & & $94.9(94.1$ to 95.8$)$ & \\
\hline \multicolumn{9}{|l|}{ Sex: } \\
\hline Men & $0.6(0.5$ to 0.7$)$ & \multirow{2}{*}{-0.12} & $11.0(8.5$ to 13.6$)$ & \multirow{2}{*}{0.34} & $9.0(8.6$ to 9.4$)$ & \multirow{2}{*}{0.001} & 86.0 (83.3 to 88.8) & \multirow{2}{*}{0.19} \\
\hline Women & $0.5(0.4$ to 0.6$)$ & & $8.9(6.5$ to 11.3$)$ & & 7.5 (7.1 to 7.9$)$ & & $84.0(81.2$ to 86.8$)$ & \\
\hline \multicolumn{9}{|l|}{ Race/ethnicity: } \\
\hline Hispanic & 0.5 (0.3 to 0.7$)$ & \multirow{5}{*}{0.02} & 4.3 (1.5 to 7.2$)$ & \multirow{5}{*}{0.001} & $11.8(10.7$ to 13.0$)$ & \multirow{5}{*}{0.001} & 90.0 (86.1 to 93.8) & \multirow{5}{*}{0.001} \\
\hline Non-Hispanic white & $0.6(0.5$ to 0.7$)$ & & $15.3(12.6$ to 18.0$)$ & & $7.0(6.7$ to 7.3$)$ & & 79.8 (77.0 to 82.7) & \\
\hline Non-Hispanic black & $0.4(0.2$ to 0.6$)$ & & 5.1 (1.9 to 8.3) & & 11.7 (10.8 to 12.6$)$ & & 89.1 (84.7 to 93.5) & \\
\hline Non-Hispanic Asian & $0.2(0.1$ to 0.4$)$ & & $1.8(0.3$ to 3.3$)$ & & 8.1 (6.8 to 9.4) & & 91.9 (85.2 to 98.6) & \\
\hline Other & 0.9 (0.3 to 1.4) & & $5.9(1.4$ to 10.5$)$ & & $12.1(9.8$ to 14.4$)$ & & 92.1 (86.8 to 97.5) & \\
\hline \multicolumn{9}{|l|}{ Education: } \\
\hline Below high school & $0.6(0.4$ to 0.8$)$ & \multirow{3}{*}{0.02} & $4.7(2.4$ to 7.1$)$ & \multirow{3}{*}{0.001} & $12.7(11.6$ to 13.8$)$ & \multirow{3}{*}{0.001} & 89.0 (84.7 to 93.2) & \multirow{3}{*}{0.001} \\
\hline High school & $0.5(0.3$ to 0.6$)$ & & 8.8 (5.8 to 11.7$)$ & & 9.3 (8.8 to 9.9) & & 87.7 (84.3 to 91.0) & \\
\hline Beyond high school & 0.5 (0.4 to 0.6$)$ & & $11.7(9.2$ to 14.2$)$ & & 7.0 (6.7 to 7.3$)$ & & 82.6 (79.7 to 85.5$)$ & \\
\hline \multicolumn{9}{|l|}{ Family income (IPR): } \\
\hline 1.0 & $0.8(0.5$ to 1.0$)$ & \multirow{4}{*}{0.60} & $9.9(5.8$ to 14.0$)$ & \multirow{4}{*}{0.09} & 13.1 (12.0 to 14.2$)$ & \multirow{4}{*}{0.001} & 83.8 (78.9 to 88.7$)$ & \multirow{4}{*}{0.41} \\
\hline $1.0-1.9$ & $0.6(0.4$ to 0.8$)$ & & 6.5 (3.9 to 9.1$)$ & & 11.6 (10.7 to 12.5$)$ & & 88.5 (84.9 to 92.1$)$ & \\
\hline $2.0-3.9$ & $0.4(0.3$ to 0.5$)$ & & $8.8(5.7$ to 11.8$)$ & & $8.4(7.9$ to 9.0$)$ & & 85.2 (81.1 to 89.3$)$ & \\
\hline 4.0 & $0.5(0.4$ to 0.7$)$ & & $13.1(9.5$ to 16.7$)$ & & $6.2(5.8$ to 6.6$)$ & & 82.6 (78.8 to 86.4$)$ & \\
\hline \multicolumn{9}{|l|}{ BMI $\left(\mathrm{kg} / \mathrm{m}^{2}\right)$ : } \\
\hline 25.0 & 0.5 (0.4 to 0.6$)$ & & 27.1 (20.6 to 33.6$)$ & & 3.3 (3.0 to 3.7 ) & & 67.1 (60.5 to 73.6$)$ & \\
\hline $25.0-29.9$ & $0.6(0.4$ to 0.7$)$ & 0.05 & $14.2(10.0$ to 18.4$)$ & 0.001 & 6.7 (6.3 to 7.2$)$ & 0.001 & $81.0(76.4$ to 85.6$)$ & 0.001 \\
\hline 30.0 & 0.5 (0.4 to 0.6$)$ & & $4.1(2.9$ to 5.3$)$ & & 14.1 (13.5 to 14.7$)$ & & 90.8 (88.9 to 92.7$)$ & \\
\hline $\begin{array}{l}\text { BMI=body mass index; IPR } \\
* \text { *Unweight number of part } \\
(n=3) \text { were excluded. } \\
\text { †All estimates were weigh } \\
\text { age groups } 20-44 \text { years, } 4 \\
\text { †P value for overall differe }\end{array}$ & $\begin{array}{l}\text { mily income to poverty rat } \\
\text { ants. Number of type } 1 \text { an } \\
\text { Overall and age group res } \\
4 \text { years, and } 65 \text { years or } \\
\text { s across stratums. }\end{array}$ & $2 \mathrm{di}$ & $\begin{array}{l}\text { ases was } 345 \text { and } 5798 \\
\text { ed, except when indicate }\end{array}$ & 8, respec & $\begin{array}{l}\text { Participants who did not k } \\
\text { esults by other stratums w }\end{array}$ & otypes & $\begin{array}{l}\text { 253) or refused to repc } \\
\text { to } 2010 \text { US census pop }\end{array}$ & $\begin{array}{l}\text { abtypes } \\
\text { ion using }\end{array}$ \\
\hline
\end{tabular}

other countries as well. ${ }^{121822-24}$ Although none of those US national surveys collected information on subtypes of diabetes, several previous studies used limited and indirect information from those surveys to estimate the prevalence of type 1 and type 2 diabetes among US adults. ${ }^{25}$ For example, using data from the National Health and Nutrition Examination Survey, one study estimated the prevalence of type 1 diabetes in the entire civilian non-institutionalized US population, including adults and children, to be 2.6 per 1000 or 3.4 per 1000 , depending on the working definitions. ${ }^{25}$ In that study, however, type 1 diabetes was assumed on the basis of age when diabetes was diagnosed ( $<30$ years, definition 1 ; or $<40$ years, definition 2 ), insulin use within one year of diagnosis, and current use of insulin. ${ }^{25}$ Another study estimated the crude prevalence of type 2 diabetes, defined as a self reported physician diagnosis of diabetes after age 30 years, in US adults across race/ethnicity groups on the basis of the Behavioral Risk Factor Surveillance System. ${ }^{26}$ The reported crude prevalence of type 2 diabetes was 9.4\% among Hispanic people, 6.9\% among non-Hispanic white people, $12.0 \%$ among non-Hispanic black people, and 5.0\% among non-Hispanic Asian people. However, classification of diabetes subtypes simply by age of diabetes diagnosis ( $<30$ years or $<40$ years) could lead to bias, as previous studies have shown that type 2 diabetes accounted for $12 \%$ of all diabetes cases in people aged <30 years. ${ }^{27}$ Moreover, a population based registry in Italy reported that the incidence of type 1 diabetes in adults aged 30-49 years was similar to that in those aged $<30$ years. ${ }^{28}$

Continued monitoring of the prevalence of type 1 and type 2 diabetes among adults is particularly important because both have increased substantially over time among children and adolescents. ${ }^{22} 29$ In the United States, the SEARCH for Diabetes in Youth study reported that between 2001 and 2009 the prevalence of type 1 and type 2 diabetes among children and adolescents increased from 1.48 to 1.93 per 1000 and from 0.34 to 0.46 per 1000 , respectively. ${ }^{30}$ Moreover, among US children and adolescents during 2002-12 the annual incidence of type 1 and type 2 diabetes increased by $1.4 \%$ and $7.1 \%$, respectively. ${ }^{31}$ It was projected that among US children and adolescents, the number of cases of type 1 diabetes would nearly triple, from 179388 in 2010 to 587488 in 2050 and the number of cases of type 2 diabetes would almost quadruple, from 22820 in 2010 to 84131 in $2050 .^{32}$ As a result, cases of type 1 and type 2 diabetes in adults will substantially increase as the children and adolescents reach adulthood. Major risk factors for type 2 diabetes, including 


\begin{tabular}{|c|c|c|c|c|}
\hline \multirow[b]{2}{*}{ Characteristics } & \multicolumn{2}{|l|}{ Type 1 diabetes } & \multicolumn{2}{|l|}{ Type 2 diabetes } \\
\hline & Adjusted odds ratio $(95 \% \mathrm{Cl}) \dagger$ & $P$ value & Adjusted odds ratio $(95 \% \mathrm{Cl}) \dagger$ & $P$ value \\
\hline \multicolumn{5}{|l|}{ Age (years): } \\
\hline $20-44$ & 1.00 (reference) & & 1.00 (reference) & \\
\hline $45-64$ & 1.18 (0.85 to 1.65$)$ & 0.32 & 0.77 (0.71 to 0.83$)$ & 0.001 \\
\hline 65 & $1.33(0.92$ to 1.93$)$ & 0.13 & & \\
\hline Sex: & & & 1.47 (1.28 to 1.69$)$ & 0.001 \\
\hline Men & 1.00 (reference) & & 1.00 (reference) & \\
\hline Women & 0.76 (0.58 to 0.99$)$ & 0.04 & $1.48(1.32$ to 1.66$)$ & 0.001 \\
\hline Race/ethnicity: & & & $1.76(1.42$ to 2.18$)$ & 0.001 \\
\hline Hispanic & $0.56(0.32$ to 0.97$)$ & 0.04 & $1.72(1.35$ to 2.18$)$ & 0.001 \\
\hline Non-Hispanic white & 1.00 (reference) & & & \\
\hline Non-Hispanic black & $0.64(0.40$ to 1.03$)$ & 0.07 & 1.00 (reference) & \\
\hline Non-Hispanic Asian & $0.34(0.16$ to 0.73$)$ & 0.005 & 0.87 (0.77 to 0.98$)$ & 0.02 \\
\hline Other & $1.13(0.59$ to 2.17$)$ & 0.71 & 0.75 (0.66 to 0.85$)$ & 0.001 \\
\hline \multicolumn{5}{|l|}{ Education: } \\
\hline Below high school & 1.00 (reference) & & 1.00 (reference) & \\
\hline High school & $0.67(0.44$ to 1.03$)$ & 0.07 & $0.90(0.78$ to 1.03$)$ & 0.12 \\
\hline Beyond high school & $0.78(0.52$ to 1.17$)$ & 0.22 & 0.67 (0.58 to 0.77$)$ & 0.001 \\
\hline Family income (IPR): & & & $0.53(0.46$ to 0.61$)$ & 0.001 \\
\hline 1.0 & 1.00 (reference) & & & \\
\hline $1.0-1.9$ & $0.70(0.43$ to 1.14$)$ & 0.15 & 1.00 (reference) & \\
\hline $2.0-3.9$ & 0.51 (0.32 to 0.79$)$ & 0.003 & 2.08 (1.84 to 2.34$)$ & 0.001 \\
\hline 4.0 & 0.59 (0.40 to 0.89$)$ & 0.01 & 5.01 (4.49 to 5.60$)$ & 0.001 \\
\hline \multicolumn{5}{|l|}{ BMI $\left(\mathrm{kg} / \mathrm{m}^{2}\right)$ : } \\
\hline 25.0 & 1.00 (reference) & & 1.00 (reference) & \\
\hline $25.0-29.9$ & 1.04 (0.74 to 1.46$)$ & 0.84 & 0.77 (0.71 to 0.83$)$ & 0.001 \\
\hline 30.0 & $0.95(0.69$ to 1.30$)$ & 0.73 & 1.47 (1.28 to 1.69$)$ & 0.001 \\
\hline
\end{tabular}

obesity, physical inactivity, and unhealthy diets are still problematic and without a notable declining trend. ${ }^{12}$ Although genetic disposition plays a critical part in type 1 diabetes, the potential role of environmental risk factors are increasingly recognized. ${ }^{13} 33$

However, dynamic changes in the proportions of type 1 and type 2 diabetes in diabetes overall are expected over time. Although type 2 diabetes is generally regarded to account for $90-95 \%$ of diabetes cases, ${ }^{1}$ the International Diabetes Federation reported that approximately $87-91 \%$ of people with diabetes in high income countries have type 2 diabetes, 7-12\% have type 1 diabetes, and 1-3\% have other diabetes subtypes. ${ }^{34}$ One study in the United States using medical claims data estimated that type 2 diabetes accounted for about $92 \%$ of cases of diabetes among insured US adults, although the results could not be generalized to the US population. ${ }^{35}$ The proportion of type 2 diabetes in cases of diagnosed diabetes in the present study (91.2\%), based on the most recent prevalence estimates in 2016 and 2017, was comparable to the previously reported prevalence. However, with the increases in prevalence ${ }^{30}$ and incidence ${ }^{31}$ of type 1 diabetes in young people, and improved treatment and extended life expectancy in those with this form of diabetes, ${ }^{36-38}$ more adults with childhood onset type 1 diabetes will live with the condition across their lifespan. Future studies with continued surveillance are needed to examine this dynamic trend.

\section{Strengths and weaknesses of this study}

The major strength of this study is the use of nationally representative data from a leading national health survey, such that the findings are representative of the US general population. In addition, the large sample size and diverse racial/ethnic population allowed us to investigate risk factors and disparities between populations with type 1 and type 2 diabetes. This study has several limitations. Firstly, information on physician diagnosis of diabetes was self reported by the participants and therefore prone to misreporting and recall bias. Previous studies, however, have shown the specificity of self reported diabetes to be more than 95\% compared with physician's medical records ${ }^{39}$ or a reference definition defined by plasma glucose level and drug use. ${ }^{40}$ Secondly, we could not rule out the possibility of participants misreporting the subtypes of diabetes. However, some major clinical characteristics reported by the participants were in line with current knowledge of reported diabetes subtypes. For example, the weighted mean age of diabetes diagnosis for those with type 2 diabetes was 47.9 years, with $89.1 \%$ of participants given a diagnosis at age 30 years or older. Most of the participants with type 1 diabetes who used insulin had initiated use within one year of diagnosis. The weighted mean age at diagnosis of type 1 diabetes among the adult participants was 28.3 years old. Although type 1 diabetes is known as "juvenile diabetes," most people with type 1 diabetes are adults. ${ }^{38} 4142$ Recent epidemiologic studies also 
showed that around half of the cases of type 1 diabetes was diagnosed after age 30 years. ${ }^{4243}$ Thirdly, this study focused on cases of diagnosed diabetes. We were unable to ascertain undiagnosed diabetes in this survey and therefore the prevalence of diabetes, including both diagnosed and undiagnosed cases, would be expected to be higher than reported in this study.

\section{Conclusions}

This study provides benchmark estimates on the national prevalence of diagnosed type 1 and type 2 diabetes among US adults. Further investigations are warranted to understand the reasons for disparities in such prevalence among subpopulations. Continued monitoring is needed to examine dynamic changes in the prevalence of type 1 and type 2 diabetes and their proportions in people with a diagnosis of diabetes in the US general population. The role of changing patterns in risk factors on the national prevalence of type 1 and type 2 diabetes also needs to be determined. Contributors: WB and GX contributed to the study design. GX analyzed the data and drafted the manuscript. All authors contributed to the interpretation of the results and revision of the manuscript for important intellectual content and approved the final version of the manuscript. WB and GX are guarantors.

Funding: This work was partly supported by a research grant from the National Institutes of Health (R21 HD091458).

Competing interests: All authors have completed the ICMJE uniform disclosure form at www.icmje.org/coi disclosure.pdf and declare: no financial relationships with any organizations that might have an interest in the submitted work in the previous three years; no other relationships or activities that could appear to have influenced the submitted work.

Ethical approval: The University of lowa institutional review board determined that the current study was exempt for ethical approval owing to the use of deidentified data.

Data sharing: No additional data available

Transparency: The lead author (WB) affirms that the manuscript is an honest, accurate, and transparent account of the study being reported; that no important aspects of the study have been omitted.

This is an Open Access article distributed in accordance with the Creative Commons Attribution Non Commercial (CC BY-NC 4.0) license, which permits others to distribute, remix, adapt, build upon this work non-commercially, and license their derivative works on different terms, provided the original work is properly cited and the use is noncommercial. See: http://creativecommons.org/licenses/by-nc/4.0/.

1 Chen L, Magliano DJ, Zimmet PZ. The worldwide epidemiology of type 2 diabetes mellitus--present and future perspectives. Nat Rev Endocrinol 2011;8:228-36. doi:10.1038/nrendo.2011.183.

2 Ogurtsova K, da Rocha Fernandes JD, Huang Y, et al. IDF Diabetes Atlas: Global estimates for the prevalence of diabetes for 2015 and 2040. Diabetes Res Clin Pract 2017;128:40-50. doi:10.1016/j. diabres.2017.03.024.

3 Centers for Disease Control and Prevention. National Center for Chronic Disease Prevention and Health Promotion. National Diabetes Statistics Report, 2017: Estimates of Diabetes and Its Burden in the United States. www.cdc.gov/diabetes/pdfs/data/statistics/nationaldiabetes-statistics-report.pdf accessed December 132017

4 Nathan DM. Long-term complications of diabetes mellitus. N Engl) Med 1993:328:1676-85. doi:10.1056/NEIM199306103282306.

5 Grundy SM, Benjamin IJ, Burke GL, et al. Diabetes and cardiovascular disease: a statement for healthcare professionals from the American Heart Association. Circulation 1999;100:1134-46. doi:10.1161/01. CIR.100.10.1134

6 Harding JL, Shaw JE, Peeters A, Cartensen B, Magliano DJ. Cancer risk among people with type 1 and type 2 diabetes: disentangling true associations, detection bias, and reverse causation. Diabetes Care 2015;38:264-70. doi:10.2337/dc14-1996.

7 Preis SR, Hwang SJ, Coady S, et al. Trends in all-cause and cardiovascular disease mortality among women and men with and without diabetes mellitus in the Framingham Heart Study, 1950 to 2005. Circulation 2009;119:1728-35. doi:10.1161/ CIRCULATIONAHA.108.829176.
8 Baena-Díez JM, Peñafiel J, Subirana I, et al, FRESCO Investigators. Risk of Cause-Specific Death in Individuals With Diabetes: A Competing Risks Analysis. Diabetes Care 2016;39:1987-95. doi:10.2337/ dc16-0614.

9 American Diabetes Association. Economic costs of diabetes in the U.S. in 2012. Diabetes Care 2013;36:1033-46. doi:10.2337/dc12 2625.

10 Bommer C, Heesemann E, Sagalova V, et al. The global economic burden of diabetes in adults aged 20-79 years: a cost-of-illness study. Lancet Diabetes Endocrinol 2017;5:423-30. doi:10.1016/ S2213-8587(17)30097-9.

11 Nathan DM. Diabetes: Advances in Diagnosis and Treatment. IAMA 2015;314:1052-62. doi:10.1001/jama.2015.9536.

12 Chatterjee S, Khunti K, Davies MJ. Type 2 diabetes. Lancet 2017;389:2239-51. doi:10.1016/S0140-6736(17) 30058-2.

13 Katsarou A, Gudbjörnsdottir S, Rawshani A, et al. Type 1 diabetes mellitus. Nat Rev Dis Primers 2017;3:17016. doi:10.1038/ nrdp.2017.16

14 Flannick J, Johansson S, Njølstad PR. Common and rare forms of diabetes mellitus: towards a continuum of diabetes subtypes. Nat Rev Endocrinol 2016:12:394-406. doi:10.1038/nrendo.2016.50.

15 Geiss LS, Wang J, Cheng YJ, et al. Prevalence and incidence trends for diagnosed diabetes among adults aged 20 to 79 years, United States, 1980-2012. JAMA 2014;312:1218-26. doi:10.1001/ jama.2014.11494.

16 Menke A, Casagrande S, Geiss L, Cowie CC. Prevalence of and Trends in Diabetes Among Adults in the United States, 1988-2012. JAMA 2015;314:1021-9. doi:10.1001/jama.2015.10029.

17 Selvin E, Parrinello CM, Sacks DB, Coresh J. Trends in prevalence and control of diabetes in the United States, 1988-1994 and 1999-2010. Ann Intern Med 2014;160:517-25. doi:10.7326/ M13-2411.

18 Wang L, Gao P, Zhang M, et al. Prevalence and Ethnic Pattern of Diabetes and Prediabetes in China in 2013. JAMA 2017;317:251523. doi:10.1001/jama.2017.7596.

19 Blackwell DL, Lucas JW, Clarke TC. Summary health statistics for U.S. adults: national health interview survey, 2012. Vital Health Stat 10 2014;(260):1-161.

20 Centers for Disease Control and Prevention. Division of Diabetes Translation. Long-term Trends in Diabetes. www.cdc.gov/diabetes/ statistics/slides/long_term_trends.pdf accessed December 6th 2017.

21 Parsons VL, Moriarity C, Jonas K, Moore TF, Davis KE, Tompkins L. Design and estimation for the national health interview survey, 2006-2015. Vital Health Stat 2 2014:(165):1-53.

22 Diaz-Valencia PA, Bougnères P, Valleron AJ. Global epidemiology of type 1 diabetes in young adults and adults: a systematic review. BMC Public Health 2015;15:255. doi:10.1186/s12889-015-1591-y.

23 Holman N, Young B, Gadsby R. Current prevalence of Type 1 and Type 2 diabetes in adults and children in the UK. Diabet Med 2015;32:1119-20. doi:10.1111/dme.12791.

24 Sharma M, Nazareth I, Petersen I. Trends in incidence, prevalence and prescribing in type 2 diabetes mellitus between 2000 and 2013 in primary care: a retrospective cohort study. BMJ Open 2016:6:e010210 doi:10.1136/bmjopen-2015-010210.

25 Menke A, Orchard TJ, Imperatore G, Bullard KM, MayerDavis E, Cowie CC. The prevalence of type 1 diabetes in the United States. Epidemiology 2013;24:773-4. doi:10.1097/ EDE.0b013e31829ef01a.

26 McNeely MJ, Boyko EJ. Type 2 diabetes prevalence in Asian Americans: results of a national health survey. Diabetes Care 2004:27:66-9. doi:10.2337/diacare.27.1.66

27 Harron KL, Feltbower RG, McKinney PA, Bodansky HJ, Campbell FM, Parslow RC. Rising rates of all types of diabetes in south Asian and non-south Asian children and young people aged 0-29 years in West Yorkshire, U.K., 1991-2006. Diabetes Care 2011;34:652-4. doi: $10.2337 /$ dc $10-1512$

28 Bruno G, Runzo C, Cavallo-Perin P, et al, Piedmont Study Group for Diabetes Epidemiology. Incidence of type 1 and type 2 diabetes in adults aged 30-49 years: the population-based registry in the province of Turin, Italy. Diabetes Care 2005;28:2613-9. doi:10.2337/diacare.28.11.2613

29 Fazeli Farsani S, van der Aa MP, van der Vorst MM, Knibbe CA, de Boer A. Global trends in the incidence and prevalence of type 2 diabetes in children and adolescents: a systematic review and evaluation of methodological approaches. Diabetologia 2013;56:1471-88. doi:10.1007/s00125-013-2915-z.

30 Dabelea D, Mayer-Davis El, Saydah S, et al, SEARCH for Diabetes in Youth Study. Prevalence of type 1 and type 2 diabetes among children and adolescents from 2001 to 2009. JAMA 2014;311:1778-86. doi:10.1001/jama.2014.3201.

31 Mayer-Davis EJ, Dabelea D, Lawrence JM. Incidence Trends of Type 1 and Type 2 Diabetes among Youths, 2002-2012. N Engl J Med 2017;377:301. doi:10.1056/NEJMc1706291 
32 Imperatore G, Boyle JP, Thompson TJ, et al, SEARCH for Diabetes in Youth Study Group. Projections of type 1 and type 2 diabetes burden in the U.S. population aged <20 years through 2050: dynamic modeling of incidence, mortality, and population growth. Diabetes Care 2012;35:2515-20. doi:10.2337/dc12-0669.

33 Rewers M, Ludvigsson J. Environmental risk factors for type 1 diabetes. Lancet 2016;387:2340-8. doi:10.1016/S0140-6736(16)30507-4.

34 International Diabetes Federation. IDF Diabetes Atlas 8th Edition 2017. www.diabetesatlas.org/component/ attachments/?task=download\&id $=254$.

35 Dall TM, Yang W, Halder P, et al. Type 2 diabetes detection and management among insured adults. Popul Health Metr 2016;14:43. doi:10.1186/s12963-016-0110-4.

36 Nishimura R, LaPorte RE, Dorman JS, Tajima N, Becker D, Orchard T). Mortality trends in type 1 diabetes. The Allegheny County (Pennsylvania) Registry 1965-1999. Diabetes Care 2001;24:823-7. doi:10.2337/diacare.24.5.823

37 Miller RG, Secrest AM, Sharma RK, Songer TJ, Orchard TJ. Improvements in the life expectancy of type 1 diabetes: the Pittsburgh Epidemiology of Diabetes Complications study cohort. Diabetes 2012;61:2987-92. doi:10.2337/db11-1625.

38 Chiang JL, Kirkman MS, Laffel LM, Peters AL, Type 1 Diabetes Sourcebook Authors. Type 1 diabetes through the life span: a position statement of the American Diabetes Association. Diabetes Care 2014:37:2034-54. doi:10.2337/dc14-1140.
39 Kehoe R, Wu SY, Leske MC, Chylack LTJr. Comparing self-reported and physician-reported medical history. Am J Epidemiol 1994;139:813-8. doi:10.1093/oxfordjournals.aje.a117078

40 Schneider AL, Pankow JS, Heiss G, Selvin E. Validity and reliability of self-reported diabetes in the Atherosclerosis Risk in Communities Study. Am J Epidemiol 2012;176:738-43. doi:10.1093/aje/ kws156.

41 Weng J, Zhou Z, Guo L, et al, T1D China Study Group. Incidence of type 1 diabetes in China, 2010-13: population based study. BMJ 2018;360:j5295. doi:10.1136/bmj.j5295.

42 Rogers MAM, Kim C, Banerjee T, Lee JM. Fluctuations in the incidence of type 1 diabetes in the United States from 2001 to 2015: a longitudinal study. BMC Med 2017;15:199. doi:10.1186/s12916017-0958-6

43 Thomas NJ, Jones SE, Weedon MN, Shields BM, Oram RA Hattersley AT. Frequency and phenotype of type 1 diabetes in the first six decades of life: a cross-sectional, genetically stratified survival analysis from UK Biobank. Lancet

Diabetes Endocrinol 2018;6:122-9. doi:10.1016/S2213 8587(17)30362-5.

Supplementary information: figure showing flow of participants through study 